\title{
Use of Internet and social media as a new communication medium among nurses
}

\author{
Türkan Işık Erer ${ }^{1}$ \\ Aslıhan Ardıç Çobaner ${ }^{2}$
}

\begin{abstract}
This study was planned with the aim of determining the usage of the Internet and social media among the nurses at the Centre of Health Research and Practice at the University of Mersin, in addition to investigating its contribution to their professional development and evaluating the usage of social media in an ethical perspective. Nurses as an employee group work very closely with society and provide services to healthy and ill individuals. They have been increasingly using both Internet and social media sources while undertaking their roles. This study is a descriptive study. A questionnaire was supplied to 260 nurses who were on duty at the hospital while the data was being collected and who agreed to participate in the research. The data acquired was analyzed using the statistical methods of arithmetic averages, percentages, standard deviations (SD) and chisquare $\left(X^{2}\right)$. The results were evaluated using a confidence interval of $95 \%$, with a level of significance of $\mathrm{p}<0.05$. The nurses who stated that they use the Internet comprised 259 of the 260 nurses that participated, while $83.8 \%$ of them used social media. According to this study, the usage of the Internet and social media for professional development is also common. The majority of the nurses accept that the usage of social media has various risks and state that there is a need for informative studies directed towards more effective usage of these tools.
\end{abstract}

Keywords: Internet, social media, social networking, nurse, ethics.

\section{Introduction}

Today the role of the Internet and social media as 'new public spheres' in which different social identities coexist, have become important to the socializing. In this new communication medium characterized as a 'network society' (Castells, 2005) individuals are connected to each other locally and globally, through the Internet and social media.

Social media may be described as 'the Internet-based applications built upon the ideological and technological foundations of Web 2.0 which enhance the user to create and share content' (Kaplan\&Haenlein, 2010:61). According to Boyd and Ellison (2007:210) on the other hand, they are network-based services founded upon the individuals (1) creating a profile which is open or half-open for the public in a connected system, (2) their preparing a list together with other individuals who have mutual connections and (3) their sharing this list with the lists which have been prepared by other users in the system and their following it.

\footnotetext{
${ }^{1}$ Assist. Prof. Dr., Mersin University, Nursing Department, turkanerer@gmail.com

2 Assist. Prof. Dr., Mersin University, Social Work Department, acobaner@gmail.com
} 
Erer, T. I., \& Çobaner, A. A. (2016). Use of Internet and social media as a new communication medium among nurses. International Journal of Human Sciences, 13(1), 1084-1093. doi:10.14687/ijhs.v13i1.3478

With the usage of social media gradually increasing in the world, their roles in the field of health such as looking for information related to health, the development of health, presentation and risk communication regarding both patients and health professionals has also gradually increased (Carillo-Larco, 2012:756). Social media has influenced the communication and interaction of people with each other in subjects related to health. Today, people ask questions regarding their health over social networks and many institutions or experts related to health respond over these networks (Kung\&Oh, 2014:64).

In Turkey, patients and health professionals usage of the Internet and social media has gradually increased. From research aiming to determine the rate and level of usage of the Internet and social media by patients and their doctors conducted in Turkey in 2011 by the Department of Clinical Quality and Medicine Safety, 95\% of doctors were active on the Internet and spared $47 \%$ of their time for scientific research (Arikan\&Benker, 2011:1).

Nurses as a group of professionals work very closely with society and provide a service to healthy and ill individuals. In undertaking these functions, they make use of the Internet and information technologies at greater rates (Kaya et al., 2008:89; Ay, 2009:131). While the increasing usage of social media in the profession of nursing has been emphasized many times, it also raises some ethical concerns. The risks relating to the professional ethics of nursing from the usage of social media may be grouped as the uncontrollable content; the violation of patient privacy and the secrecy of personal information; unprofessional behavior and organizational risks (Barry\&Hardiker, 2012; Canadian Nurses Association, 2012; The Nursing and Midwifery Board of Australia, 2010).

It is important that nurses' attention is drawn to the ethical principles of nursing in relation to the usage of social media and the Internet. As a result, many guides and documents dealing with the usage of social media are being developed by various institutions, associations and professional organizations in the field of nursing. In 2011, The American Nurses Association (ANA) included the usage of social media in its reviewed code of ethics and published the Social Networking Principles Toolkit. In this guide it underlines the importance of the professional principles of occupational ethics in relation to digital/online mediums; the not sharing of the identity of patients, patient records, photographs and other information in online mediums; taking timely action against ethical problems such as the violation of privacy; the reporting of issues and the need for nurses to be part of institutional policy developments regarding online applications (The American Nurses Association, 2011).

\section{Purpose}

The aim of this study is to determine the reasons for usage of the Internet and social media by the nurses at the Centre of Health Research and Practice at the University of Mersin in Turkey and their views regarding the risks which can be encountered on an ethical dimension.

\section{Methods and Material}

The universe of research consists of the study 320 nurses who were on duty between the dates of 1 October 2014 and 1 February 2015 at the Centre of Health Research and Practice of the University of Mersin. The calculation of the sample size was done using the MedCalc statistical package program and accepting alpha $=0.05$ the power of the test $=0.80$, minimum sample width was calculated as at least 130 in every group. The study population consisted of 260 nurses who were on duty at the hospital while the data was being collected and who agreed to participate in the research.

The questionnaire consisted of 21 questions which were prepared to determine descriptive personal information; the reasons for usage of the Internet and social media and the risks and ethical problems identified through the researchers knowledge of literature. The time to complete the questionnaire was 20 minutes on average and a pilot study was conducted with 10 nurses prior 
Erer, T. I., \& Çobaner, A. A. (2016). Use of Internet and social media as a new communication medium among nurses. International Journal of Human Sciences, 13(1), 1084-1093. doi:10.14687/ijhs.v13i1.3478

to the final version. The nurses who completed the pilot study were not included in the final sample. The questionnaire was given to the nurses participating in the research, with information about the aims and methods of the study and on receipt of verbal consent, the form was completed in the presence of the researchers.

Following application, permission was received from the Board of Ethics of the Health Sciences Department of the University of Mersin and the Centre of Health Research and Practice of the University of Mersin in order to conduct the investigation. The data collected was analyzed using the statistical methods of arithmetic averages, percentages (\%), standard deviation (SD) and Chisquare $\left(\mathrm{X}^{2}\right)$. The results were evaluated using a confidence interval of $95 \%$, and a level of significance of $\mathrm{p}<0.05$.

\section{Results}

\section{Demographic and Background Information of Participants}

Of the 260 nurses who participated in the research, $82.3 \%(n=214)$ of them are women. Of the participants $36.1 \%(n=94)$ were in the age group 31-40 years and $6 \%(n=16)$ of them in the range $41-46$ years, the average age being 29 years $(\mathrm{ss}=6$, minimum $=18$, maximum $=46)$. Those working as a nurse between 1 and 9 years came to $65.7 \%(n=171) ; 7 \%(n=18)$ of them 20 years or more, the average duration in the profession being 7.9 years ( $\mathrm{ss}=6.5$; minimum $=1$ year, maximum $=28$ years). Graduates comprised $79.2 \%(\mathrm{n}=206)$ of participants, only $6.2 \% \quad(\mathrm{n}=16)$ held post-graduate qualifications, $66.2 \%(\mathrm{n}=172)$ work as bed-side patient care nurses (Table 1).

The rate of the participants who have expressed that they use the Internet in their daily lives is $99.6 \%(n=259)$ and those having access to the Internet at their work places $92 \%(n=239)$. In response to the question regarding where they access the Internet from, 36.2\% ( $n=94)$ of the participants stated that they access from the hospital, home and mobile telephone.

Of the participants who use the Internet to a great extent, $95.8 \%(\mathrm{n}=249)$ of them use it for 'accessing information resources'; $68.8 \%(\mathrm{n}=169)$ of them for 'watching/listening to video/music'; $61.9 \%(n=161)$ of them for 'check e-mails'; $59.2 \%(n=154)$ of them for 'using the social media (Facebook-Twitter etc.)'; 48.1\% $(\mathrm{n}=125)$ of them for 'banking transactions' and 36.5\% ( $\mathrm{n}=95)$ of them for 'shopping'.

The participants who use the Internet every day is $72.7 \%(\mathrm{n}=189) ; 3-4$ days a week $24.2 \%$ ( $n=63)$. While the ones who use the Internet between 1 and 3 hours a day are $46.9 \%(n=122)$; the ones using it for less than 1 hour are $45.2 \%(n=117)$ (Table 1).

\begin{tabular}{|c|c|c|c|c|c|c|c|c|c|}
\hline \multicolumn{2}{|c|}{ Identifying Characteristics } & \multicolumn{2}{|c|}{$\begin{array}{l}\text { Used Social } \\
\text { Media }\end{array}$} & \multicolumn{2}{|c|}{$\begin{array}{l}\text { Did Not Use } \\
\text { Social Media }\end{array}$} & \multicolumn{2}{|c|}{ Total } & \multirow[b]{2}{*}{$\mathbf{X}^{2}$} & \multirow[b]{2}{*}{$\mathbf{P}$} \\
\hline & & $\mathrm{n}$ & $\%$ & $\mathrm{n}$ & $\%$ & $\mathrm{n}$ & $\%$ & & \\
\hline \multirow[t]{3}{*}{ Sex } & Female & 178 & 81.6 & 36 & 85.7 & 214 & 82.3 & 0.399 & 0.528 \\
\hline & Male & 40 & 18.3 & 6 & 14.3 & 46 & 17.7 & & \\
\hline & Total & 218 & 100 & 42 & 100 & 260 & 100 & & \\
\hline \multirow{5}{*}{ Age } & $18-25$ & 66 & 30.2 & 5 & 11.9 & 71 & 27.3 & 7.093 & 0.69 \\
\hline & $26-30$ & 66 & 30.2 & 13 & 30.9 & 79 & 30.4 & & \\
\hline & $31-40$ & 73 & 33.4 & 21 & 50 & 94 & 36.1 & & \\
\hline & $41-46$ & 13 & 5.4 & 3 & 7.1 & 16 & 6.1 & & \\
\hline & Total & 218 & 100 & 42 & 100 & 260 & 100 & & \\
\hline \multirow{5}{*}{$\begin{array}{l}\text { Educational } \\
\text { status }\end{array}$} & High school & 11 & 5 & 2 & 4.8 & 13 & 5 & 1.645 & 0.649 \\
\hline & Associate & 23 & 10.5 & 2 & 4.8 & 25 & 9.6 & & \\
\hline & Graduate & 171 & 78.4 & 35 & 83.3 & 206 & 79.2 & & \\
\hline & Post-graduate & 13 & 6 & 3 & 7.1 & 16 & 6.2 & & \\
\hline & Total & 218 & 100 & 42 & 100 & 260 & 100 & & \\
\hline
\end{tabular}


Erer, T. I., \& Çobaner, A. A. (2016). Use of Internet and social media as a new communication medium among nurses. International Journal of Human Sciences, 13(1), 1084-1093. doi:10.14687/ijhs.v13i1.3478

\begin{tabular}{|c|c|c|c|c|c|c|c|c|c|}
\hline \multirow[t]{4}{*}{$\begin{array}{l}\text { Working } \\
\text { position }\end{array}$} & $\begin{array}{l}\text { Bedside patient } \\
\text { care }\end{array}$ & 143 & 65.5 & 29 & 69 & 172 & 66.2 & 0.741 & 0.389 \\
\hline & Nurse managers & 29 & 13.3 & 4 & 9.5 & 33 & 12.7 & & \\
\hline & Other* & 46 & 21.1 & 8 & 19 & 54 & 20.8 & & \\
\hline & Total & 218 & 100 & 42 & 100 & 260 & 100 & & \\
\hline \multirow{4}{*}{$\begin{array}{l}\text { Working } \\
\text { years }\end{array}$} & $<1-9$ & 145 & 66.5 & 25 & 14.7 & 171 & 65.7 & 0.967 & 0.617 \\
\hline & 10-19 & 57 & 26.1 & 14 & 19.8 & 71 & 27.3 & & \\
\hline & $20-29$ & 15 & 6.9 & 3 & 16.7 & 18 & 7 & & \\
\hline & Total & 218 & 100 & 42 & 100 & 260 & 100 & & \\
\hline \multirow{5}{*}{$\begin{array}{l}\text { Hours of } \\
\text { using the } \\
\text { Internet per } \\
\text { day }\end{array}$} & $<1$ hour & 88 & 40.3 & 29 & 69 & 117 & 45.2 & 12.171 & 0.007 \\
\hline & 1-3 hours & 111 & 50.9 & 10 & 23.8 & 122 & 46.9 & & \\
\hline & 4-6 hours & 14 & 6.4 & 2 & 4.8 & 16 & 6.2 & & \\
\hline & 7 hours $>$ & 4 & 1.8 & 1 & 2.3 & 5 & 1.9 & & \\
\hline & Total & 218 & 100 & 42 & 100 & 260 & 100 & & \\
\hline
\end{tabular}

*Other fields such as polyclinic, surgery room, nutrition, wound care, colonoscopy, gastroenterology, bloodtaking unit.

\section{The Comparison of the States of Usage of the Social Media}

While $83.8 \%(n=218)$ of participants state that they use social media; the usage of the social media is $87 \%(\mathrm{n}=40)$ among male nurses. When the states of using and not using social media are compared according to the descriptive characteristics of the participants, no meaningful difference was found between gender and use of social media $\left(X^{2}=0.399, p=0.528\right)$ (Table 1).

The most frequently used social media sources are Facebook 80.8\% ( $\mathrm{n}=210)$ and Google+ $42.7 \%(n=111)$, while the least frequently used are Linkedln $5.4 \%(n=14)$ and blogs $5 \%(n=13)$. The biggest difference between social media use by male and female nurses is related to the usage of YouTube and Twitter. Usage of YouTube among the men is $41.3 \%$ compared to $26.2 \%$ among women. Men use Twitter at a rate of $43.5 \%$ and women at a rate of $30.8 \%$ (Table 2). Two thirds of social media usage occurred among the 18-30 age group; with the highest usage rate among those with 1-9 years' work experience (Table 1).

When asked their frequency of social media use, $65.8 \%(n=171)$ of participants stated that they use it every day and $1.5 \%(n=4)$ of them once in 3-4 months. When on the other hand they were asked about their durations of usage in a day, $40.3 \%(\mathrm{n}=88)$ stated that that they use it for under one hour; $50.9 \%(n=111)$ of them between 1 and 3 hours and $8.2 \%(n=18)$ of them between 4 and 6 hours and above (Table 1).

When the reasons for using social media were questioned, the greatest rate of $71.5 \%(n=186)$ of the participants said that it was for 'receiving information related to their friends'; $63.5 \%(n=165)$ of them for 'reading news'; $60 \%(\mathrm{n}=156)$ of them for 'sharing a message'; $55 \%(\mathrm{n}=143)$ of them that for 'sharing photographs'; $48.5 \%(\mathrm{n}=126)$ of them for being informed about professional activities' and $41.2 \%(n=107)$ for 'getting information about developments related to health' (Table 2).

In the questions related to professional development and the ethical dimension of the usage of social media, $72.7 \%(n=189)$ of participants think that social media has a role in developing professional social networks and relationships for the profession of nursing. The rate of the participants who expressed their awareness of the platforms of the profession of nursing, blogs of it, nursing groups and the association pages related to nursing in the social media is $70 \%(\mathrm{n}=182)$; while those following these pages on the other hand came to $57.3 \%(n=149)$.

Of the participants who use social media, those that share information related to nursing and health aimed at society is $46.9 \%(\mathrm{n}=122)$. Those sharing emotional moments (happy/sad) related to their professions on the other hand is $26.9 \%(n=70)$. Only $6.2 \%(n=16)$ of participants stated that 
Erer, T. I., \& Çobaner, A. A. (2016). Use of Internet and social media as a new communication medium among nurses. International Journal of Human Sciences, 13(1), 1084-1093. doi:10.14687/ijhs.v13i1.3478

they share information/photographs related to patients for whom they provide care; $81.3 \%(\mathrm{n}=13)$ of these had received consent related with this sharing.

Of the participants, $80 \%(\mathrm{n}=208)$ believe that using social media has various risks. Of these risks it was expressed that 'inaccurate information' posed the greatest risk $62.7 \%(\mathrm{n}=163)$; followed by 'unprofessional behavior' at $58.1 \%(\mathrm{n}=151)$; 'the violation of patient privacy' at $53.8 \%(\mathrm{n}=140)$ and on the other hand 'the organizational risks' at 33.8\% ( $\mathrm{n}=88$ ) (Table 2). Regarding these risks only $26.5 \%(n=70)$ of participants expressed a need for informative education or guidelines regarding the use of social media.

Table 2: Using Social Media Tools, Reasons and Risks

\begin{tabular}{l|cc|}
\hline Social Media Tools & $\mathbf{n}$ & $\mathbf{\%}$ \\
\hline Facebook & 210 & 80.8 \\
Google+ & 111 & 42.7 \\
Twitter & 86 & 33.1 \\
YouTube & 75 & 28.8 \\
Linkedln & 14 & 5.4 \\
Blogs & 13 & 5 \\
\hline Reasons & & \\
\hline Receiving information related to their friends & 186 & 71.5 \\
Reading news & 165 & 63.5 \\
Sharing a message & 156 & 60 \\
Sharing photographs & 143 & 55 \\
Being informed about professional activities & 126 & 48.5 \\
Getting information about the developments related with health & 107 & 41.2 \\
Find old friends & 103 & 39.6 \\
Listen and download music & 103 & 39.6 \\
Chat & 86 & 33.1 \\
Sharing professional information, articles and codes of practice & 80 & 30.8 \\
Locating on the ground notifications & 57 & 21.9 \\
To access online nursing groups & 77 & 29.6 \\
Playing games & 56 & 21.5 \\
Making job applications & 37 & 14.2 \\
Following blogs & 36 & 13.8 \\
\hline Risks & & \\
\hline Inaccurate information & 163 & 62.7 \\
Unprofessional behaviour & 151 & 58.1 \\
The violation of patient privacy & 140 & 53.8 \\
Organizational risks & 88 & 33.8 \\
\hline n: Multiple options are marked. & & \\
& & \\
\hline
\end{tabular}

\section{Discussion}

The majority of the participants in the study are women and between aged $31-40$ years. Those with professional experience of between 1 and 5 years came to $45 \%$ and the average years of experience 7.9 years. According to the data from the Survey of the Usage of Information Technology in Households by the Turkish Statistical Institute in 2014 the usage rate of the Internet in Turkey is $53.8 \%$. This rate is comprised of $63.5 \%$ men and $44.1 \%$ women (TurkStat, 2014). The 
Erer, T. I., \& Çobaner, A. A. (2016). Use of Internet and social media as a new communication medium among nurses. International Journal of Human Sciences, 13(1), 1084-1093. doi:10.14687/ijhs.v13i1.3478

usage of the Internet by the participants in this study is above the average of Turkey. The younger age profile of the participants affects the usage rates of technology in a positive way.

In Turkey, the rate of nurses using the Internet every day is $72.7 \%$, above the average of Turkey at $71.2 \%$ (TurkStat, 2014). The participants in our study use the Internet most frequently between 1 and 3 hours (46.9\%) and less than 1 hour (45\%). In the study by Kung and Oh (2014:66) the finding that more than half of the nurses spent between 1 and 4 hours a day on the Internet, is similar to the nurses' duration of Internet usage in Turkey. The high Internet usage by participants has important implications regarding their professional development and interactions. ${ }^{5}$

In this study one third (36.2\%) of the participants stated that they access the Internet from the hospital, home and mobile telephones. However, despite the majority of participants $(92 \%)$ having declared that they have Internet access in the work place, a small proportion (3.1\%) connect to the Internet only at the hospital. This suggests that the nurses spend most of their working hours in patient care and treatment and that they use the Internet and social media outside working hours.

In Turkey, the Internet is used predominantly with the aim of joining social groups (Facebook, Twitter etc.) (78.8\%); reading online news, newspapers, magazines (74.2\%) and looking for information about goods and services $(67.2 \%)$ (TurkStat, 2014). This study shows that nurses use the Internet mostly $(95.8 \%)$ with the aim of reaching sources of information. This is positive with regard to improving the quality of care provided and their desire to access current professional information.

Worldwide studies indicate that health professionals follow social media closely. In a metaanalysis including doctors, nurses, dentists, chemists and medical students in England, it was found that the use of social networks and Facebook was common; Facebook usage among medical students was $65-96 \%$, while among other health professionals it was $13-47 \%$ (Von Muhlen\&Ohno-Machado, 2012: 777). A study undertaken of 711 nurses by the College of Nurses of Ontario in Canada in 2012 revealed that $77 \%$ of nurses use social media (2012:15). A study of students from universities in Australia that receive education in the health professions has ascertained that Facebook usage is high among all the students (Usher et al., 2014:96). In this study the rate of social media usage was $83.2 \%$ among nurses. This widespread usage offers important opportunities regarding professional development and interaction.

According to our study in Turkey the nurses use social media mostly with the aim of communication, being informed and entertainment. Moreover the usage of social media with the aim of professional development is also rather widespread. The nurses accept that social media has a role in developing professional social networks and relationships within the profession of nursing $(72.7 \%)$. Among these are being informed of professional activities, getting information about developments related to health, sharing professional information, essays, legal issues and reaching nursing groups.

In the world it is seen that social media (Linkedln $(46 \%)$ and Facebook $(42 \%)$ ) is frequently used among nurses looking for work (AMN Healthcare, 2013:15). Contrary to this it can be seen that in Turkey social media usage with the aim of looking for work or making job applications is at a low rate $(14.2 \%)$. The reason for this rate being low may be that nurses are not facing any issues finding employment at present in Turkey.

Three quarters of the participants expressed an awareness of the platforms for the profession of nursing, blogs, nursing groups and professional association pages in the social media; more than half of them actually follow these pages. Accessing correct, reliable, current communication sources related to their profession quickly and easily, has an important role for professional communication and organization. The importance of these tools to the professional development of the nursing 
Erer, T. I., \& Çobaner, A. A. (2016). Use of Internet and social media as a new communication medium among nurses. International Journal of Human Sciences, 13(1), 1084-1093. doi:10.14687/ijhs.v13i1.3478

profession, indicated by the numbers following these pages emphasizes the need for education and informative studies directed towards their effective usage.

Social media is also a forum where emotions can be expressed, represented and support can be received from colleagues and support groups (Cronquist\&Spector, 2011:38). At the same time it provides nurses with important opportunities to communicate with their colleagues and educators in different regions of the world (Bary\&Hardiker, 2012). In this study almost half of the participants stated that they have shared information related to nursing and health oriented topics on social media. More than one quarter of these related to experiences and emotional moments connected to their work. This sharing will strengthen nurses' communication with society in Turkey and their colleagues around the world.

The high usage of social media by the nurses in this study has also raised some concerns regarding ethics. In the study more than three quarters of the participants hold the view that using social media has various risks. The majority of the participants have indicated that the first of these risks is 'inaccurate information'. In general, serious concerns prevail in relation to the lack of control over the information present on the Internet. On social media some poor/incorrect practices related to health can be represented as 'correct practices' and this may result in both health professionals and patients' making wrong decisions (Bary\&Hardiker, 2012). This situation besides threatening the health of the individual, diminishes the reliability of the health professionals and may increase health expenditure and prolong recovery periods as a result of the poor quality of information.

More than half of the participants think that social media constitutes a risk related to 'the violation of patient confidentiality'. Information shared on social media spreads in a short time and quickly. The violations of privacy and confidentiality done intentionally or unintentionally may have very serious consequences for nurses, patients and employers. Patient confidentiality besides being one of the most important values to be protected comprises the foundation of nursing values. The process of informing and taking consent in medical ethics is the most important feature of the principle of autonomy and the respect for autonomy in medical practice (Oguz, 1999). The first function of the consent process is to protect the patient and render his/her autonomous choice possible.

The participants have described other risks as 'unprofessional behavior' and 'organizational risks'. While the expressions and images shared on social media affect patient confidentiality, they may also consist of unprofessional behaviors targeting colleagues, employers and managers. One of the nurses' professional responsibilities is to maintain a boundary between their private and professional lives. However, this boundary becomes uncertain especially during online activities. These violations may come into existence in many different ways such as sharing comments, videos or photographs humiliating patients (NCSBN, 2011:3; Andersen\&Puckrin, 2011:36). This situation may cause organizational risks which can damage both the nursing profession and the institutional reputation. Within the context of the risks described it can be said that the nurses using social media take into consideration ethical principles. However, they need to know that in the case of ethical violations their patients and profession can suffer.

More than one quarter of the participants indicated that in the context of the risks mentioned above they need informative education or guidelines regarding the usage of social media. Worldwide, the number of ethical principles and informative guides oriented towards the usage of social media is increasing. In 2011 The American Nurses Association (ANA), included the usage of social media, reviewed its ethical codes and published the "Social Networking Principles Toolkit" (2011). The Mayo Clinic prepared a social media users' guide directed towards its staff and opened this for online access for all of its staff (http://sharing.mayoclinic.org/guidelines/for-mayo-clinicemployees $/$ ). Presently and in future the ethical problems created by the usage of social media 
Erer, T. I., \& Çobaner, A. A. (2016). Use of Internet and social media as a new communication medium among nurses. International Journal of Human Sciences, 13(1), 1084-1093. doi:10.14687/ijhs.v13i1.3478

need to be taken into consideration. It is important that in Turkey the professional principles of nursing be reviewed and the ethical principles of "confidentiality and privacy, consent taking" be taken into consideration in relation to the use of social media (Cobaner\&Erer, 2014:145).

\section{Conclusion and Recommendations}

The Internet and social media as a new communication medium are frequently being used by the majority of the nurses in Turkey. This study provided a preliminary review on how frequently nurses utilize Internet and social media and the characteristics of nurses who used Internet and social media based on a survey. While the nurses use the Internet mostly with the aim of getting information, communication and entertainment, the majority of them are conscious that the Internet and social media have a role in developing professional social networks and relationships as well as various risks.

Nurses may use social media differently depending on the purposes they have, such as for receiving information related to their friends, reading news, sharing a message and photos, being informed about professional activities, getting information about the developments related with health and professional development. Additionally, according to the results of the research it is important that the nurses be supported regarding the use of the Internet and social media. In this matter the policy makers, professional associations, educational institutions and employers in the health field have a duty. Presently and in the future, the professional principles of nursing, the ethical principles of 'confidentiality and privacy, consent taking' have to be reviewed in relation to the usage of social media. Also there is need for studies in this field to be conducted by the policy makers, the universities and professional associations and for the researchers to include larger populations and a greater depth of investigation.

Future research in this area is a need for qualitative and quantitative researches which will encompass a lot of nurses from more different regions oriented towards the social media tools which the nurses frequently use. Moreover the health service being given with a team perspective be taken into consideration, it will be useful that also the comparative studies directed towards the nurses and the other health professionals be done.

\section{References}

AMN Healthcare. (2012). Use of Social Media and Mobile by Healthcare Professionals: 2011 Survey Results. http://www.amnhealthcare.com. Accessed on: March 16, 2015.

Anderson, J, Puckrin, K. (2011). Social network use: A test of self-regulation. Journal of Nursing Regulation; 2(1): 36-41. http://jnr.metapress.com/content/512267w22r102645. Accessed on: April 1, 2015.

Arikan, Y., Benker, T. (2011). Internet and social media impacts on Turkish health care professionals' reaching health and drug side effect related information. Drug Saf, http://www.boehringeringelheim.com.tr/content/dam/Internet/opu/tr_TR/documents/ pdf. Accessed on: April 6, 2015.

Ay, F. (2009). International electronic patient record systems and relationship between nursing practices and computer. Gulhane Med Journal.51(2): 131-136.

Barry, J, Hardiker, N. (2012). Advancing Nursing Practice Through Social Media: A Global Perspective. The Online Journal of Issues in Nursing (OJIN) 17 (3). http://www.nursingworld.org/MainMenuCategories/ANAMarketplace/ANAPeriodicals/ OJIN/TableofContents/Vol-17-2012/No3-Sept-2012/Advancing-Nursing-ThroughSocial-Media. html. Accessed on: March 16, 2015. DOI: 10.3912/OJIN.Vol17No03Man05 
Erer, T. I., \& Çobaner, A. A. (2016). Use of Internet and social media as a new communication medium among nurses. International Journal of Human Sciences, 13(1), 1084-1093. doi:10.14687/ijhs.v13i1.3478

Boyd, D.M, Ellison N.B. (2007). Social network sites: definition, history, and scholarship. Journal of Computer-Mediated Communication, 13(1): 210-230. Accessed on: March 16, 2015. DOI: 10.1111/j.1083-6101.2007.00393.x

Canadian Nurses Association (CNA). (2012).When private becomes public: The ethical challenges and opportunities of social media. http://www2.cnaaiic.ca/CNA/documents/pdf/publications/Ethics_in_Practice_Feb_201 2_e.pdf. Accessed on: March 16, 2015.

Carillo-Larco, R.M. (2012). Social networks and public health: use of Twitter by ministries of health, International Journal of Public Health, 57(57): 755-756. 756. http://link.springer.com/article/10.1007\%2Fs00038-012-0387-4. Accessed on: May 1, 2014. DOI: $10.1007 /$ s00038-012-0387-4.

Castells, M. (2005). The Information Age: Economy, Society and Culture: The Rise of the Network Society. Vol. I. Istanbul Bilgi University Publications.

Cobaner, AA, Erer T.(2014). Discussing the benefits and risks of social media use among nurses in the context of medical ethics. Turkish Journal of Bioethics (TJOB), (1): 137-148. Accessed on: March 1, 2015. http://www.journalagent.com/tjob/pdfs/TJOB-86580-REVIEWARDIC_COBANER.pdf. DOI: 10.5505/tjob.2014.86580 .

College of Nurses of Ontario.(2012) Survey says... Nurses weigh in on social media. The Standard, 37(2): 14-15. http://www.cno.org/Global/4LearnAboutStandardsAndGuidelines, No2.pdf. Accessed on: May 15, 2015.

Cronquist, R., Spector, M.(2011). Nurses and Social Media: Regulatory Concerns and Guidelines. Journal of Nursing Regulation, 2(3): 37-40. www.journalofnursingregulations.com. Accessed on: March 14, 2015. DOI: 10.3912/OJIN.Vol17No03Man01

Kaplan, AM., Haenlein, M. (2010). Users of the world, unite! The challenges and opportunities of social media. Business Horizons, 53(1): 59-68. DOI:10.1016/j.bushor.2009.09.003

Kaya, N, Asti, T, Kaya, H, Kaçar, GY. (2008).Views of nurses about computer usage. Istanbul University Florence Nightingale Nurse School Publications, 16(62): 83-89.

Kung, YM.,Oh, S. (2014). Characteristics of nurses who use social media. Computers, Informatics, $\begin{array}{lll}\text { Nursing } & \text { (CIN), } & \text { 64-72. }\end{array}$ http://journals.lww.com/cinjournal/Fulltext/2014/02000/Characteristics_of_Nurses_Wh O_Use_Social_Media.4.aspx. s. 64. Accessed on: March 14, $2015 . \quad$ DOI: 10.1097/CIN.0000000000000033

Mayo Clinic. (2015). For Mayo Clinic Employees. http://sharing.mayoclinic.org/guidelines/formayo-clinic-employees/ Accessed on: March 14, 2015.

National Council of State Boards of Nursing (NCSBN). (2011) White paper: A nurse's guide to the use of social media. https://www.ncsbn.org/Social_Media.pdf. Accessed on: March 14, 2015.

Oguz, N.Y. (1999).Principle of respect for autonomy (Informed Consent). Deontology, Arda B, Oguz Y, Pelin S.S. Second Edition, Ankara: An Publications.

The American Nurses Association (ANA). (2011).Fact sheet navigating the world of social media. http://www.nursingworld.org/FunctionalMenuCategories/AboutANA/SocialMedia/Social-Networking-Principles-Toolkit/Fact-Sheet-Navigating-the-World-of-SocialMedia.pdf. Accessed on: March 14, 2015.

The Nursing and Midwifery Board of Australia (NMBA). (2010). Information Sheet on Social Media. 
Erer, T. I., \& Çobaner, A. A. (2016). Use of Internet and social media as a new communication medium among nurses. International Journal of Human Sciences, 13(1), 1084-1093. doi:10.14687/ijhs.v13i1.3478

http://www.nursingmidwiferyboard.gov.au/Search.aspx?q=information $\% 20$ sheet $\% 20$ on $\%$ 20social\%20media. Accessed on: March 14, 2015.

Turkish Statistical Institute (TUIK). (2014). Information and Communication Technology (ICT) Usage Survey in Households and Individuals- 2014, http://www.tuik.gov.tr/PrehaberBultenleri.do?id=16198. Accessed on: March 16, 2015.

Usher, K, Woods, C, Casella, E. et al. (2014). Australian health professions student use of social media. Collegian, 21(2), 95-101. http://dx.doi.org/10.1016/j.colegn.2014.02.004. Accessed on: March 14, 2015.

Von Muhlen, M., Ohno-Machado L. (2012). Reviewing social media use by clinicians. Journal of the American Medical Informatics Association, 19(5):777-81. DOI:10.1136/amiajnl-2012000990 . 